\title{
RH HAEMOLYTIC DISEASE OF THE NEWBORN, 1960-1961
}

\author{
BY \\ PETER M. DUNN* \\ From the Maternity Hospital, Birmingham
}

(RECEIVED FOR PUBLICATION JUNE 4, 1963)

Before 1941, erythroblastosis foetalis was treated at Birmingham Maternity Hospital by repeated intramuscular injections of fresh blood (Braid, 1939). During the next decade infants with $R h$ haemolytic disease of the newborn were given repeated intravenous transfusions of $R h$ negative blood. The exchange transfusion was not introduced until 1950. The first three years' experience (1950-53) with this new technique was reviewed by Davies, Gerrard, Hatchuel and Howarth in 1953.

Two years' experience of $\mathrm{Rh}$ haemolytic disease at the same hospital a decade later forms the subject of this paper.

\section{Methods}

Haemoglobin $(\mathrm{Hb} \quad 100 \%=14.8$ g. $/ 100 \mathrm{ml}$.) was estimated as oxyhaemoglobin by a photoelectric absorptiometer (Unicam) and serum bilirubin by the Lathe and Ruthven (1958) modification of the diazo method.

Exchange transfusions were performed through the umbilical vein using Henderson's apparatus (1950). Where possible the tip of the catheter was advanced until it was felt to pass through the ductus venosus into the inferior vena cava, usually a distance of approximately $3 \frac{1}{2}$ in. $(9 \mathrm{~cm}$.). Warm, fresh, citrated, two-thirds packed donor blood was used. Individual $10 \mathrm{ml}$. volumes were exchanged until a total of $80-100 \mathrm{ml}$./lb. $(175-220 \mathrm{ml} . / \mathrm{kg}$.) had been reached; $5 \mathrm{ml}$. volumes were used when the infant was very small or sick. Clotting in the apparatus was prevented by regular flushing with heparinized saline. The infant was kept comfortable by laying him, with the minimum of restraint, on a pillow warmed by an electric blanket or, occasionally, by performing the transfusion through the port-hole of an incubator. Oxygen was administered to all severely affected infants with the aid of a small 'perspex' hood. Digoxin was given by intramuscular injection if there was evidence of heart failure. Signs suggestive of tetany due to citrate intoxication were counteracted with calcium gluconate. The 'exchange' usually took

* Present address: Bristol Maternity Hospital, Bristol. one and a half to two hours, but was extended for several hours when necessary.

Simple transfusions were given by slow injection into a scalp vein of $10-15 \mathrm{ml}$. per $\mathrm{lb}$. $(22-36 \mathrm{ml} . / \mathrm{kg}$.) body weight of fully packed $\mathrm{Rh}$ negative blood.

\section{Clinical Material}

During 1960 and 1961, 4,754 babies were born at the Birmingham Maternity Hospital. $3 \cdot 8 \%$ of all babies delivered suffered from $\mathrm{Rh}$ haemolytic disease in contrast to the national average of $0.5 \%$. The booking policy probably resulted in a greater proportion of severely affected infants than would be expected.

The fate of the 215 babies born to women with $\mathrm{Rh}$ antibodies is summarized in Fig. 1. Of these, 35 infants $(16 \%)$ were $\mathrm{Rh}$ negative and unaffected. The Coombs test on the remaining $180(84 \%)$ was positive. Incompatibility was due to $R h$ ' $D$ ' in all cases except three in which either Rh ' $E$ ' (2) or Rh 'c' (1) was implicated. Of the affected infants, $14(7 \cdot 7 \%)$ were stillborn and a further nine died $(5 \%)$, bringing the perinatal mortality to $12 \cdot 7 \%$. One clinical diagnosis of early kernikterus was made.

The cord blood findings of the 166 liveborn babies are shown in Fig. 2 in relation to exchange transfusion therapy, the development of obstructive jaundice and mortality. 86 infants $(51.9 \%)$ did not require an exchange transfusion. Of the remaining 80 babies $(48 \cdot 1 \%), 47$ received one and 33 two exchange transfusions. Three of the latter required yet a third exchange, bringing the total to 116 exchanges.

'Early' exchange transfusion within nine hours of birth (Walker, 1961) was performed 69 times. The remaining 11 first and the 36 repeat exchange transfusions were performed because the indirect reacting bilirubin level rose or threatened to rise over $20 \mathrm{mg}$./ $100 \mathrm{ml}$. $88 \%$ of the exchange transfusions were performed during the first 48 hours of life and $98 \%$ before the age of 72 hours.

All the nine infants that died did so during the first day of life, two within minutes of birth, two during exchange transfusion, and five later. No baby with a cord-blood haemoglobin over $75 \%(11.0 \mathrm{~g} . / 100 \mathrm{ml}$.) died. Half the 12 babies with cord blood haemoglobins 
below $50 \%$ ( $7.4 \mathrm{~g} . / 100 \mathrm{ml}$.) survived, one of these having a haemoglobin of $25 \%(3.7 \mathrm{~g} . / 100 \mathrm{ml}$.) at birth.

Simple transfusion for late anaemia, defined as a haemoglobin below $45-50 \%$ after the first week of life, was required by 17 infants, or $10.7 \%$ of the survivors. Five infants who had not previously received an exchange transfusion, required a simple transfusion during the first month but not thereafter (Fig. 3). Eleven infants who had previously received an exchange transfusion, required simple transfusion between the fourth and seventh weeks. Over half (six) had shown evidence of obstructive jaundice.

From an analysis of the babies' weight, the haemoglobin before and after transfusion and the volume of blood given in these cases, it was found that for every $1 \mathrm{ml}$. of packed blood/lb. $(2 \cdot 2 \mathrm{ml} . / \mathrm{kg}$.) body weight transfused, the haemoglobin was raised on the average by $3.6 \%(0.53 \mathrm{~g} . / 100 \mathrm{ml}$.), the range being $2 \cdot 5-5 \cdot 0 \%$

While outside the scope of this paper, it might be of interest to add that during this two-year period eight babies received exchange transfusions for hyperbilirubinaemia due to either ABO incompatibility (four) or associated with prematurity (four). One late transfusion was given for anaemia of prematurity.

\section{Discussion}

The changes in the incidence of $\mathrm{Rh}$ haemolytic disease, its management and mortality at the Birmingham Maternity Hospital between 1950-53 and 1960-61 are shown in the Table.

TABLE

CHANGES IN INCIDENCE, MANAGEMENT AND MORTALITY OF RH HAEMOLYTIC DISEASE AT BIRMINGHAM MATERNITY HOSPITAL BETWEEN 1950-1953 AND 1960-1961

\begin{tabular}{|c|c|c|}
\hline & $1950-1953$ & $1960-1961$ \\
\hline $\begin{array}{l}\text { Average number of babies with } \mathbf{R h} \\
\text { haemolytic disease per year } \ldots \\
.\end{array}$ & 33 & 90 \\
\hline $\begin{array}{cccc}\text { Babies receiving } & \text { exchange } & \text { transfusion } \\
\text { therapy }(\%) & . & . & .\end{array}$ & 40 & $48 \cdot 1$ \\
\hline $\begin{array}{l}\text { Babies receiving repeat } \\
\text { fusion }(\%) \\
\text { exchange trans- }\end{array}$ & $4 \cdot 2$ & 20 \\
\hline $\begin{array}{ccccc}\text { Babies receiving } & \text { simple } & \text { transfusion } \\
\text { only }(\%) & . . & . & . & \cdots\end{array}$ & 20 & 3 \\
\hline $\begin{array}{l}\text { Babies receiving no transfusion therapy } \\
\begin{array}{lllll}(\%) & . & . & . & .\end{array}\end{array}$ & 40 & $48 \cdot 9$ \\
\hline Perinatal mortality $(\%) \quad \ldots \quad \ldots$ & 34 & $12 \cdot 7$ \\
\hline Incidence of kernikterus (\%) & $4 \cdot 5$ & $0 \cdot 6$ \\
\hline
\end{tabular}

The number of babies with $\mathrm{Rh}$ haemolytic disease delivered in this hospital increased nearly threefold in a decade. This was probably in the main due to improved prenatal diagnosis and also to the attempt to deal with this problem in a few large centres (Walker and Mollison, 1957; Walker, 1958). However, it is possible that there has been an actual

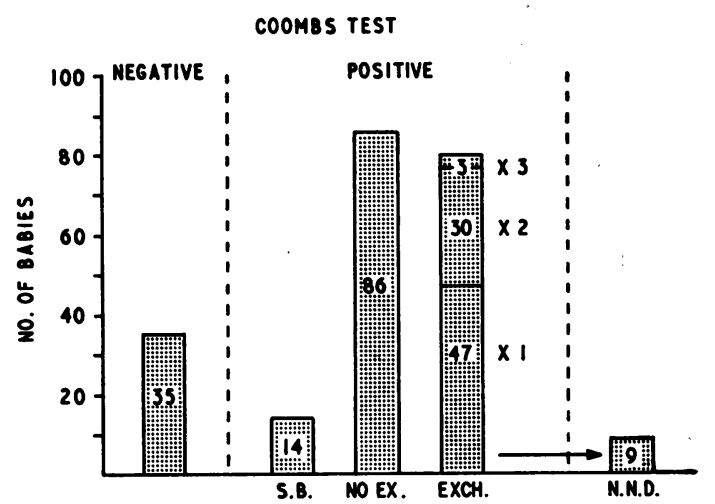

FIG. 1. - The fate of 215 babies born to women with rhesus antibodies at Birmingham Maternity Hospital, 1960-61. The babies requiring exchange $t$ ransfusion are shown divided according to whether one, two or three transfusions were required. (S.B. = stillbirths; N.N.D. = Neonatal deaths.)

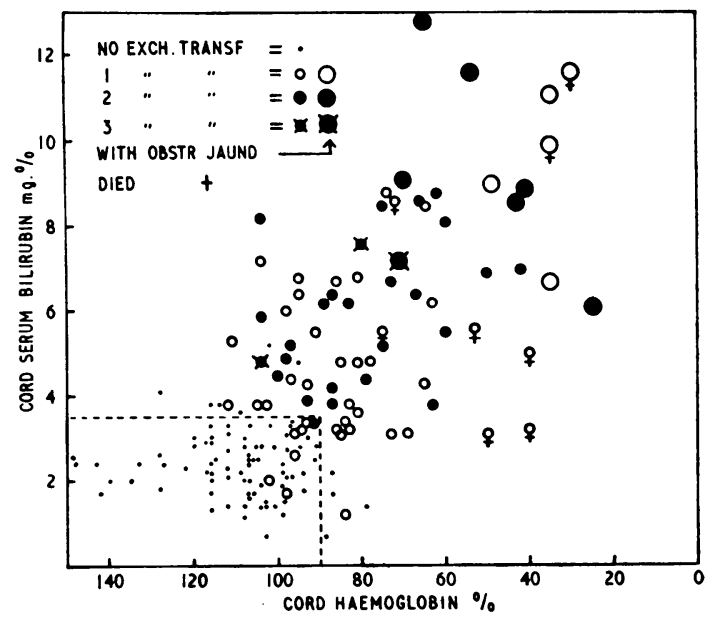

FIG. 2.-The cord blood findings of 166 liveborn babies with $\mathbf{R h}$ haemolytic disease born at Birmingham Maternity Hospital, 1960-61, in relation to exchange transfusion therapy, obstructive jaundice and mortality.
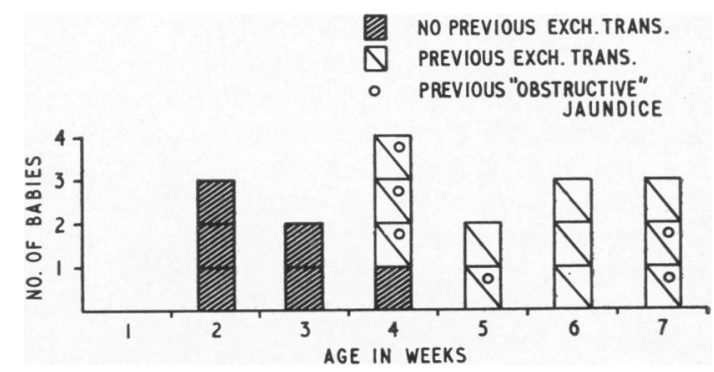

FIG. 3.-The influence of previous exchange transfusion on the timing of 17 transfusions for late anaemia of $\mathrm{Rh}$ haemolytic disease at Birmingham Maternity Hospital, 1960-61. The incidence of previous obstructive jaundice is also indicated. 


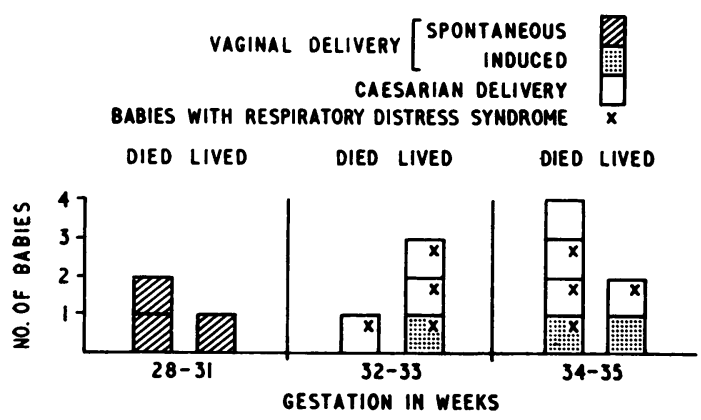

FIG. 4.-The fate of 13 babies with $\mathrm{Rh}$ haemolytic disease of less than 36 weeks' gestation born at Birmingham Maternity Hospital, 1960-61. The cause of the premature delivery and the incidence of the respiratory distress syndrome are shown.

increase in incidence. If this is so, it might be due to modern trends in the management of the third stage of labour. If the umbilical cord is clamped before the uterus is well contracted, a considerable quantity of foetal blood may remain in the placenta. Rupture of the foetal placental vessels into the maternal sinuses and sensitization might then more easily follow expulsive uterine contractions, especially if these are enhanced by the use of ergometrine.

The fivefold increase in the annual number of exchange transfusions from $11(1950-53)$ to 58 (1960-61) reflects both the increased preference of exchange to simple transfusion and the realization that repeated exchange transfusions are often necessary (Diamond, Allen, Vann and Powers, 1952). Also the decrease in the perinatal mortality indicates that an increased number of severe cases survives to require transfusion.

The perinatal mortality depends largely on the prenatal management. At this hospital it was usual to leave these women to reach term and then to induce labour when necessary. Premature induction or delivery by caesarian section was mainly reserved for those cases with a past history of rhesus stillbirth or very severely affected infant, or where clinical examination, knowledge of the father's genotype, liquor amnii and maternal antibody studies suggested that the baby was at severe risk. The mortality among 13 babies delivered before 36 weeks' gestation (Fig. 4) was 10 times as high as for the whole series, accounting for seven of the nine deaths. The susceptibility of these babies, usually severe cases delivered by caesarian section, to develop the respiratory distress syndrome was undoubtedly a major factor. Because of these results, delivery before 36 weeks was, in the latter half of this series, rarely practised, but it was on occasion followed by success. For example, a mother with a past history of two premature hydropic stillbirths was delivered by caesarian section at 33 weeks of a prehydropic infant. After two exchange transfusions and in spite of respiratory distress syndrome, the infant survived.

Without selective premature delivery, the neonatal mortality might have been reduced, but the stillbirth rate would almost certainly have risen more. Our policy resulted in a survival rate of $87 \cdot 3$, which stands comparison with the $84 \%$ reported from Newcastle (Walker, 1959) and the $87.8 \%$ from Bristol (Tovey and Valaes, 1959) and appears to have struck a fair balance between the increased hazards of prematurity and the risks of intrauterine death.

Of the 23 perinatal deaths in this series, 14 infants were either stillborn or delivered in a hydropic state before the 37th week of gestation and a further baby was an anencephalic. It could be argued that only the remaining eight infants $(4.8 \%$ of the series) had a chance of survival with different management.

The decision to perform an 'early' exchange transfusion used to be made entirely on the cord blood findings. This has been found to result in a number of unnecessary transfusions, for as Walker (1961) has shown, a 'wait and watch' policy for infants with cord haemoglobins above $77 \%$, $11.5 \mathrm{~g} . / 100 \mathrm{ml}$., was not only safe but might be of benefit. In this series, both cord blood findings and clinical judgement was used in deciding whether to transfuse, and the high proportion of babies not receiving exchange transfusion $(51.9 \%)$ without ill effects vindicates this policy. Walker (1959) states that $40 \%$ of affected infants do not require any transfusion therapy at all. In this series, the figure was $48.9 \%$. In retrospect, babies that showed clinical evidence of haemolytic disease such as jaundice, hepatosplenomegaly or pallor due to anaemia during the first nine hours, required an exchange transfusion. Prematurity alone was not an indication but acted as a bias in borderline cases. From Fig. 2 it can be seen that the need for exchange transfusion could have been predicted in $90 \%$ of cases by the cord blood findings of a haemoglobin below $90 \%$ combined with a serum bilirubin above $3.5 \mathrm{mg} . / 100 \mathrm{ml}$. The needs of the remaining $10 \%$ and the need for repeat exchange transfusion were only recognized by observation, in particular of the rate of rise of the serum bilirubin. As a working hypothesis, it was considered that the serum bilirubin would 'peak' in a full-term baby at 60 hours of age and in a baby of 36 weeks' gestation at 80 hours. By using a graph (Fig. 5) containing these data, it was possible to anticipate the likelihood of hyperbilirubinaemia and, where necessary, transfuse 
in advance. This method implies that a rise of serum bilirubin greater than $0.3 \mathrm{mg}$./hour in a mature baby $(0.2 \mathrm{mg}$./hour at 36 weeks' gestation) was potentially dangerous. Although this is a considerably lower criterion than the rate of 0.5 $\mathrm{mg}$./hour recommended as a guide by Walker (1959) and Adelman, Bell, Giunta, Barrett, Bellin and Appleton (1959), its use in this series was not reflected by a high 'exchange' rate. The value of this hypothesis was supported by the fact that only $3 \%$ of the exchange transfusions were performed on babies more than 60 hours old.

No baby was ever considered too ill to transfuse and, with the exception of the two infants that died, the full exchange was always completed. Unexplained deaths during exchange transfusion as described by Forfar, Keay, Elliott and Cumming (1958) and Walker (1959) were not seen, an adequate cause of death being apparent for the two babies that died. One had a cerebral birth injury and the other died from heart failure due to severe anaemia (cord blood $\mathrm{Hb}, 40 \%, 5.9 \mathrm{~g} . / 100 \mathrm{ml}$.) and an overrapid transfusion. Air embolism, umbilical infection and portal vein thrombosis were not encountered.

The baby who showed signs of kernikterus did so at the age of 48 hours after receiving three full exchange transfusions. At the time his indirect reacting serum bilirubin level was $20.9 \mathrm{mg} . / 100 \mathrm{ml}$. though owing to an error in estimation we believed it to be lower. This infant showed signs of slight muscular incoordination and selective deafness at the age of 1 year.

The follow-up of babies with haemolytic disease may be difficult when there are long distances to travel. The data on simple transfusion for late anaemia in this series (Fig. 3) may help to indicate what supervision is necessary. The high incidence of severe anaemia amongst babies that had exhibited the 'inspissated bile syndrome' is worth re-emphasizing. This condition, in which obstructive jaundice develops, occurred in approximately $8 \%$ of the babies with $\mathrm{Rh}$ haemolytic disease and was considered to be due to liver damage (Dunn, 1963).

\section{Summary}

The management of 180 infants with $\mathrm{Rh}$ haemolytic disease of the newborn at a maternity hospital during 1960 and 1961 is described and discussed. The perinatal mortality was $12 \cdot 7 \%$ and there was one case of kernikterus.

The changes in the incidence of this disease, and its

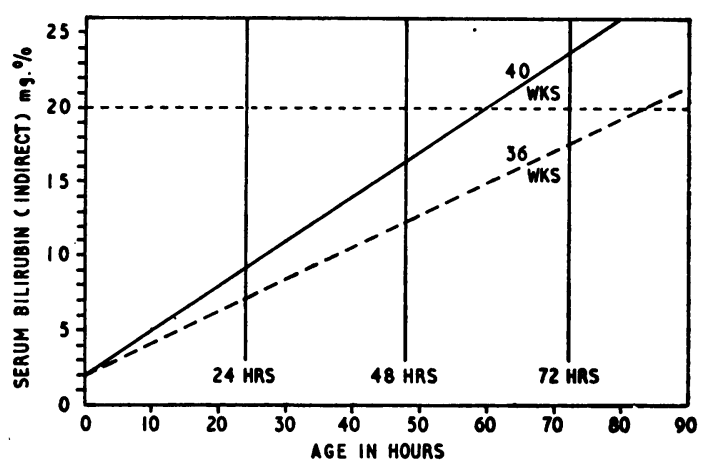

FIG. 5.-Graph to show the maximal 'safe' rate of increase of serum indirect-reacting bilirubin in babies of 36 and 40 weeks' gestation (see text).

management and mortality at this hospital during the past decade are reviewed.

I wish to thank the nurses, obstetricians, paediatricians, students and laboratory staff who helped in the care of these babies, and in particular, Dr. B. S. B. Wood for permission to publish this material and for his helpful criticism; also Mr. A. L. Deacon, F.R.C.S., the obstetrician in charge of the 'Rhesus Clinic' since its formation in June 1961. By their unfailing help Dr. W. Weiner, his staff at the B.T.S. and many blood donors made this work possible.

I am grateful for the receipt of a grant from the United Birmingham Hospitals endowment fund, for photographic assistance from Mr. W. Hurt, and to Miss V. Macdonald for her secretarial help.

\section{REFERENCES}

Adelman, M., Bell, W. J., Giunta, F., Barrett, J. L., Bellin, L. B. and Appleton, R. (1959). Practical management of erythroblastosis fetalis in a community hospital. J. Amer. med. Ass., 169, 825.

Braid, F. (1939). Some disorders of the newborn. Med. Press, $201,321$.

Davies, B. S., Gerrard, J., Hatchuel, W. L. F. and Howarth, B. E. (1953). Haemolytic disease of the newborn with special reference to exchange transfusion, 1950-1953. Bgham med. Rev., n.s., 18, 77.

Diamond, L. K., Allen, F. H., Vann, D. D. and Powers, J. R. (1952). Erythroblastosis fetalis. Pediatrics, 10, 337.

Dunn, P. M. (1963). Obstructive jaundice and haemolytic disease of the newborn. Arch. Dis. Childh., 38, 54.

Forfar, J. O., Keay, A. J., Elliott, W. D. and Cumming, R. A. (1958). Exchange transfusion in neonatal hyperbilirubinaemia. Lancet, 2, 1131 .

Henderson, J. (1950). Exchange transfusion apparatus. ibid., 2, 291 .

Lathe, G. H. and Ruthven, C. R. J. (1958). Factors affecting the rate of coupling of bilirubin and conjugated bilirubin in the van den Bergh reaction. J. clin. Path., 11, 155.

Tovey, G. H. and Valaes, T. (1959). Prevention of stillbirth in Rh haemolytic disease. Lancet, $2,521$.

Walker, W. (1958). The changing pattern of haemolytic disease of the newborn (1948-1957). Vox Sang. (Basel), n.s., 3, 225. the newborn (1948-1957). Vox Sang. (Basel), n.s., 3, 225. as a community problem. Brit. med. Bull., 15, 123.

as a community problem. Brit. med. Bull., 15, 123. - (1961). "Early" exchange transfusion. Brit. med. J., 2, 1513. Deaths in England and Wales during 1953 and 1955 . Lancet, 1, 1309. 